\title{
Attributes of motorbike racers: A case study on Malaysian Cub Prix
}

\author{
Syarizal A.R*, Razli Che Razak, Nurshadira M.R, Norailis A.W, Wan Mohd Nazdrol \\ Faculty of Entrepreneurship and Business, University Malaysia Kelantan,16100 Pengkalan Chepa, Kelantan, Malaysia
}

Correspondence Author: Syarizal A.R, Faculty of Entrepreneurship and Business, University Malaysia Kelantan,16100 Pengkalan Chepa, Kelantan, Malaysia E-mail: Syarizal.ar@umk.edu.my

Received date: 29 August 2019, Accepted date: 19 November 2019, Online date: 22 November 2019

Copyright: () 2019 Syarizal A.R et al, This is an open-access article distributed under the terms of the Creative Commons Attribution License, which permits unrestricted use, distribution, and reproduction in any medium, provided the original author and source are credited.

\begin{abstract}
The purpose of this study is to describe about the physical fitness of elite young Cub prix riders in Malaysia. These are the essential element to endure riders while competing to be the best of all. Where the rider's physical fitness compromises the reflects for speed, arm endurance, arm strength, running speed, flexibility, leg strength and leg speed. Other than that, there are few motor performance fitness tests which is plate tapping, bent arm hang, arm pull, sit and reach, stand high and to identify the health level that a Cub prix rider has to sustain themselves among European riders. Our study compromises by exploring the opportunities of Cub prix riders compared to European riders. Qualitative study was conducted in this paper and in-depth interview was carried out in collecting data. This study will investigate informant without guidance using subjective information. The qualitative method is used in this study and unstructured open ended question was used. Qualitative method is suitable to build new theory and explore new areas of this study. A finding indicates that respondents are aware on their fitness level as to perform well during races. Besides that, there are benchmarks of body mass index (BMI) weight in the range of $50 \mathrm{~kg}$ to 65 $\mathrm{kg}$. Most of the informants agreed that a racer need to have strong discipline in doing training, usually rider need to do a training 4 hours every day. The training normally carried out indoor and outdoor.
\end{abstract}

Keywords: Motorbike, Fitness, Motorsport, Training, Racers.

\section{INTRODUCTION}

Riders play a significant role at the elite level. This study enfolds the physical characteristics of Cub Prix riders in Malaysia. Moreover, the first Cub Prix race held on May 8, 1994, in Malacca. This paper is to describe the physical fitness of elite young Cub Prix riders compared with the Grand Prix riders of Italy and Spain. Where the rider's physical fitness compromises their arm speed, arm endurance, arm strength, running speed, flexibility, leg strength and leg speed. Professional riders in these motorsports are likely to spend a large part of the competitive season riding on the continental or international competition circuit. The rider's success comes from generating power that efficiently translated into the movement against the rolling resistance of the road, aerodynamic resistance, and in the case of uphill riding, gravity. Motorsport rides have been accessible middle of the 20th century and its gaining popularity among children and adolescents. The Malaysian Cub Prix Championship is a national-level under-bone dashing arrangement for cruisers with removals from the cub Prix championship which is (115cc to 130cc). The competition is a grassroots designer with the primary goal of finding and creating Malaysian cruiser hustling abilities. This paper will benefit the future and upcoming individuals to secure information should they plan to embark on this journey to be a racer. The attribute of a physical body will help the coaches to obtain an idea of an ideal person that suitable for racing agenda.

However, Motorsport is a prominent universal game with an unrivaled worldwide group of onlookers. This is especially imperative in motorsport, where such aptitudes may be vital to execution and damage lessening. (Schneiders et al., 2010). On the other hand. As the riders enhanced their riding abilities, gatherings will be balanced so that the speed and difficulty of preparing were kept up all through the program at a protected and appropriate level for all riders. Other than that, riders wellness are additionally measured through their heart rate, height, and Global Positioning System figured speed and separation which is gathered all through the landscape rides (Burr, Jamnik, \& Gledhill, 2011). 
Percentage of body fat was calculated using the estimation of body density from the sum of 4 skinfold measurements (Durnin \& Womersley, 2007). Moreover, grip strength was measured using a dynamometer (Smedley Hand Dynamometer, Stoelting Co, Wood Dale) adjusted to the second knuckle of the hand. Three trials were performed per hand in an alternating sequence and maximal value was recorded. Food composition databases are used by food and nutrition professionals to assess the dietary status to plan and evaluate the dietary adequacy of meals and diets. Accurate assessment of the intake of nutrients and other food components depends on the accuracy of the databases (Pennington et al., 2007). Dietary one of the successful sport's performance is consumed good nutrition. (American Dietetic Association, 2009).

\section{METHODOLOGY}

\section{Research Design}

For the research design, the researcher is about to explore more on the fitness level of that cub Prix riders and how they maintain their performance in kind of their habits.

\section{Sampling Strategy}

Researcher can use several techniques to have them as the researcher is referring to the research objectives. And then, the researcher will take the sampling technique that good and most suitable. Sampling is the only way where the researcher will get the information to answer our research questions. Sampling is useful when the researcher cannot obtain information from the much population. The researcher used a purposive sampling method in conducting this exploratory research and will be focusing on collecting rich information through face to face interviews. Exploratory research when data is difficult to collect. It is usually gathered specifically for the study.

\section{The Coaches}

Being in motorsport at the school level will definitely require a coach because it is not easy to handle and began with. The coaches mostly are from the retired riders which have gained a lot more experience. As a result, the coach or that trainer can be the interviews respondent to get information.

\section{The Riders}

The riders are the person who is in charge and assigned to ride the motorcycle in a race. They have been trained and always getting ready to face the motorsport world before allowing themselves to join any game in participating in local events, national or international levels. So, they will be the main subject to be respondents of this study.

\section{Data Collection Method}

The researchers have to observe and assess the riders on how their lifestyle going on in terms of the dietitian habitual, fitness exercise and how they maintain all those things. The researchers will also go to the one of school that trains for these motorcycle's riders to interview them and get the facts on what the researcher already observe. This interview also can help invalidate the result of observation and survey before about all those kind things influence to the riders.

In planning the fieldwork, the researcher should plan the strategy to ensure that time will require completion with data collection. Sampling plan can be influenced by fieldwork because they have a link with each other. In doing fieldwork, the researcher needs a sampling area and sample size which is the researcher need to target where and who the researcher wants to observe and interview. The researcher will be visiting the race venue to proceed with data collection.

\section{Data Analysis Process}

In this study, the researchers using a qualitative method which is semi-structured interviews, the researcher will interview and explore more about the riders and the coaches about their fitness. The sample will complete the interviews on a one-on-one basis. Data will be analysed on the fitness, training and diets of the riders. Research has been done by conducting semi-structured interviews with the cub Prix riders and also the coach for the rider. The researchers successfully manage to get eight respondents of the cub Prix riders. Data has been collected through the three aspects which are fitness, training and also about the coaches of the riders. From the cub Prix riders, the researcher got to know that fitness is crucial for every rider to maintain their fitness level which will give an impact on their race. If the riders are very fit, then they can give good performance during the race.

\section{Section I: Demographics}

\section{RESEARCH FINDINGS}

\begin{tabular}{l|ll}
\multicolumn{2}{l}{ Table 4.1 } \\
RIDERS & Demographic of Respondent \\
\hline $\mathbf{1}$ & 17 & GENDER \\
$\mathbf{2}$ & 22 & Male \\
$\mathbf{3}$ & 19 & Male \\
$\mathbf{4}$ & 22 & Male \\
$\mathbf{5}$ & 26 & Male \\
$\mathbf{6}$ & 32 & Male \\
$\mathbf{7}$ & 21 & Male \\
\end{tabular}


Based on the table, all informants are male and the average age is 23 years old. All of the informants are involved in racing professionally on a full-time basis. They represent various teams and sponsors.

Table 4.2 Demographic of Respondent

\begin{tabular}{l|ll} 
COACH & AGE & GENDER \\
\hline $\mathbf{8}$ & 41 & Male
\end{tabular}

From table 4.2, the researchers conducted a face to face interview with only one coach which is having a vast experience internationally. The coach has shifted from various teams on a contract basis annually.

\section{Section II: Training}

According to all respondents, training is significant for a racer as the researchers went off with the off-road as their training. Training is vital for a Cup Prix racer to maintain their fitness level before and after their race. Being a top racer's practicing cycling dumbbell, jogging and running, it will also cover the heartbeat level and increase their cardiovascular fitness. Daily workout must be at least 2 hours daily.

\section{Gym}

\section{Respondent 2:}

Their training still got but very little. Every day in the duration of 2 hours if there are no other busier jobs to be done. The main exercises in on playing a Dumbbell, jogging and also cycling at the housing areas. We will be exercising during the weekends. I also got to go to the gym to exercise and also cycling to maintain my stamina during the ride.

\section{Respondent 3:}

For a racer, physical training is needed. Cycling and jogging are for endurance during a race, so stamina is maintained forever. Using a piece of gym equipment is also important and motorcycle training is not so important. Usually, I have a motorcycle race during the weekends only. If it's a normal day then it is for physical training only.

\section{Respondent 7:}

'At least one hour of exercise, I think it is enough because if the researcher usually exercises 5 hours a day. For example, our morning mornings come in 2 hours, 2 hours and half a day.

\section{Visual Gaming}

According to these riders, playing video games is very effective for the racers during the race because it will control their imagination, focus and also the effectiveness of their performance during the game. In European countries, they practice video games at least 2 times per week. Video games are practiced very rarely in Malaysia so it's a must for the riders in Malaysia to apply this training technique to perform them well during their race.

\section{Respondent 1:}

I used to play video games to stay focused where it will be useful for me during the race to focus on the race.

\section{Respondent 3:}

At night when I am free, I will play games to make sure my focus is good. This is one of the training methods also vital for racer. It is actually a kind of video gaming.

\section{Respondent 5:}

As for me, playing games gave me the advantages in terms of staying focus on the circuit during the race. Imagination will be nurtured during the gaming race. Actually, playing games is not mandatory but if it is applied in Malaysia among the rider's then it will be very helpful for them to be successful.

\section{Section III: Fitness}

All respondents are very aware of their fitness level. Fitness is something that has to be very good and stable for the rider's so that they could perform the well during their race. Besides that, there are benchmarks of body mass index (BMI) in the range of $50 \mathrm{~kg}$ to $65 \mathrm{~kg}$. This weight range will be a perfect range for a rider to control their body weight according to the motorcycle weight. To maintain this body weight, the riders have to maintain their fitness level to keep them fit and maintain their BMI.

\section{Respondent 1:}

To maintain the fitness of the body then we have to follow daily regular exercises for example like jogging, playing dumbbell and also video games. When at first my weight was $45 \mathrm{~kg}$ but now has increased to $60 \mathrm{~kg}$ which is the ideal weight that a rider should have. All these are important to maintain fitness. 


\section{Respondent 4:}

I have a trainer, where the trainer will train me at least twice in a month to have a race on the track to give the riders the use to it. Besides that, I also go jogging, I do push-ups, cycling and other exercises that can make me fit always.

\section{Respondent 7:}

If to tell that I had a coach previously was not really to say because my father was my coach. My dad is a retired rider. For this era, the researcher doesn't really need coaches to train ourselves because its all are already set based on the data for the rider.

\section{Section IV: Diet}

Respondents prefer for a diet. Dieticians will show on when the rider's having training, is there energy that will help them with that, while, the training will affect their fitness level. These entire three factors are the main factor in how to be a good rider in proper way. Based on respondent experiences, they need to be more careful with their dietary mostly when the race was near. So, they didn't eat unhealthy food because to make their stamina still strong and unhealthy food actually not only will make a body have a bad fat, it also makes a body in pain. Drinking more water gives them more oxygen and energy for a rider. Eating healthy foods before race keeps the racer safe. A portion of food that gives energy is more important before and during exercise.

\section{Respondent 2:}

Normally I will have heavy meals. Usually I eat whatever I want based on my desires. During the race, I will really control my entire food intake where I don't take oily foods and also spicy foods because it is not good for the stomach and also during the ride. Previously I took protein intake only but now I have stopped it.

\section{Respondent 6:}

Riders are not allowed to consume all those oily foods, too much of fat food and other improper food intakes. We are allowed to take steam food and also grilled foods where that is way healthier for a rider to keep them fit. A week before the race, riders have to take note on their sleep, food intakes, good sleep and also calm down with good focus.

(Based on respondent experiences, they need to be more careful with their dietary mostly when the race was near. So, they didn't eat unhealthy food because to make their stamina still strong and unhealthy food actually not only will make a body have a bad fat, it also makes a body in pain. Drinking more water gives them more oxygen and energy for a rider. Eating healthy foods before race keeps the racer safe.)

\section{- Improper Diet}

These 2 riders are not really keen on their diets because they feel that food is not an important prospect to be a successful rider. They can have any food they want because they have the thought that whatever they eat can be discovered with their continuous training such as daily training to make them fit. So, food is not the main reason for them not to be a successful rider.

\section{Respondent 1:}

Usually, we don't follow the proper diet because we believed that our body mass will never increase due to regular exercise and activities in sports. Usually, food intakes can be consumed anything that I want and training will only start a month to race.

\section{Respondent 3:}

As for me, I do not really follow a strict diet on my food intake. Whatever we like we just consume without considering the fats and calories. The most important is to do regular exercise so food intake should not have any problem. Certain riders they really follow on a strict diet while there are also riders like me who really don't bother on the food intake.

\section{DISCUSSION AND SUGGESTIONS}

In this past research states that the bike riders with a lack of physical characteristics cause the riders like motorcycle rider crashes. So in this research, the researcher tries finding the main factor to overcome the issue of motorcycle rider crashes which is they need to be more disciplined in doing a diet, fitness and training technique in the best way.

\section{Fitness}

Based on the study, the researcher found out about the fitness of the rider who cares about their fitness, respondents believed that to stay longer and maintain stamina at the track without crashes is about their fitness level. Fitness in motorsport is different from another sport because they need to maintain their fitness mentally and physically from the beginning of the race until the race ends because they did not have rest time in the middle of the race.

\section{Training}

Rider needs to be disciplined in doing training, usually rider need to do a training 4 hours every day. The training actually has indoor and outdoor. The example of outdoor is running, cycling, swimming, gym and motor-cross tracking in the juggle indoor such as games to increase their mental level which is the game will make the rider more focus and imagination. Actually being a 
rider, they need to focus on each part of their body because the upper body handles the bike and lower body to balance the body when they in a corner.

\section{Characteristics}

The characteristic which is discipline is one of an important thing to be a rider because the rider needs to arrange their own schedule to be a winner. They didn't have a proper coach because they have many riders. So, riders have to manage themselves in terms of diet, fitness and training.

The limitation that the researcher needs to go through is where this fieldwork is conducted out of our university, thus the researcher needs to go to the location as the researcher chooses Jempol's Cub Prix track as the location. Here also, this research was quite challenging to the researcher as this research requires more direct interviews of the respondents with their full cooperation. During this time, the researcher had hard times to meet due to timing factor and it is their qualifying time for their final race on the next day so that the informants cannot provide us more time.

\section{Visual Gaming}

From the research findings, the researcher founds that most informants are not having enough exercise for themselves to be excellent rider. The researcher suggests an option to the rider to focus more on video games where it is already applicable in European countries.

\section{The Weather Changes}

Besides that, the researchers suggested that the riders continue with training in any weather. No matter in any condition either it is the wet or hot sun. This is because; in European countries, this way of training is very effective. After all, they do their training in four seasons. It boosts their energy and their body are accepting the training so they are always fit. This should be a concern applicable to the riders in Malaysia. In Malaysia, if it is raining the rider will never go out for training and this will affect their fitness level and thus continuous training in any weather changes is suggested to be applicable.

\section{Different Category of Respondents}

For this research, the researcher researchers only focused on the Cub Prix riders in Malaysia. Besides that, the researchers do not manage to interview all racers, so in future research, the researcher suggested talking on more riders because it will be constructive for us to collect more information on the data collection. Moreover, the researchers suggest researching different categories of racers for example, Supersport and superbike riders and also motorcycles with varying sizes of the engine. So, wide information can be collected through these entire racers on their fitness level and the type of training to make them become a successful rider.

\section{CONCLUSION}

Motorsport rides have been popular in the middle of the 20th century and its gaining popularity among adolescents. This study enfolds the physical characteristics of cub Prix riders, the training technique which can help the rider to be the best. Thus, fitness and training are essential for cub Prix riders so they can achieve more in the motorsport field. In order being fit they can maintain their health level by following up on the pieces of training and fitness practices.

According to the United Nations Sports for Development and Peace, physical activity plays an important role in the development of overall health and prevents various diseases. Apart from preventing diseases, following up training and fitness practices helps in improving the functional capabilities of the body. The qualitative approach to data collection is discussed in great depth, which includes of use of interviews and group focus. The steps undertaken by the researcher will begin with the aims of the research, the identification of the sample and data analysis.

\section{REFERENCES}

Article in Magazine

Francis, M. M. (2016). SIZE MATTERS. Motorcycle Culture.

Websites

https://powersports.honda.com/2017/cbr1000rr.aspx

https://en.wikipedia.org/wiki/Honda_CBR1000RR

https://en.wikipedia.org/wiki/Yamaha_YZF-R1

Journal Article

A Mendez-Villanueva, J. P.-L., D Bishop, B Fernandez-Garcia, R Ortolano, X Leibar \& N Terrados. (2005). Upper body aerobic fitness comparison betthe researcheren two groups of competitive surfboard riders. J Sci Med Sport, 8:1, 43-51.

Baggs, D., Yu, T. H., Haley, B., Benny Chiang, B., Chau, N., Wu, J. Liu, C. Y. (2013). Anteater Racing AR8 “Savage” 2015 FSAE Vehicle. 
Burr, J. F., Jamnik, V. K., \& Gledhill, N. (2011). Physiological fitness and health adaptations from purposeful training using offroad vehicles. European Journal of Applied Physiology, 111(8), 1841-1850. doi: 10.1007/s00421-010-1817-8

Dingle, G. (2009). Sustaining the race: a review of literature pertaining to the environmental sustainability of motorsport. International Journal of Sports Marketing and Sponsorship, 11(1), 75-91. doi: 10.1108/ijsms-11-01-2009-b006

Durnin, J. V. G. A., \& Womersley, J. (2007). Body fat assessed from total body density and its estimation from skinfold thickness: measurements on 481 men and women aged from 16 to 72 Years. British Journal of Nutrition, 32(01), 77-97. doi: $10.1079 /$ bjn19740060

Fisher, A. D. (1984). The structure and substance of automobile racing, or how hi-tech keeps its greasy side down. Canadian Review of Sociology \& Anthropology, 21(3), 318.

Grange, J. T., \& Cotton, A. (2004). Motorsports medicine. Current sports medicine reports, 3(3), 134-140.

Gobbi, A. W., Francisco, R. A., Tuy, B., \& Kvitne, R. S. (2005). Physiological characteristics of top level off-road motorcyclists. Br J Sports Med, 39(12), 927-931; discussion 931. doi: 10.1136/bjsm.2005.018291

JAMIE F. BURR1, V. J., \& NORMAN GLEDHILL1. (2010). A cross-sectional examination of the physical fitness and selected health attributes of recreational all-terrain vehicle riders and off-road motorcyclists. Journal of Sports Sciences, 28(13), 1423-1433. doi: 10.1080/02640414.2010.510847

Jans, C., Peersman, G., Peersman, B., Van Den Langenbergh, T., Valk, J., \& Richart, T. (2015). Endoscopic decompression for chronic compartment syndrome of the forearm in motocross racers. Knee Surg Sports Traumatol Arthrosc, 23(9), 25222527. doi: 10.1007/s00167-014-3044-Z

Jeff T. Grange, M. a. A. C., Md. (2004). Motorsports Medicine. Current Science Inc, 3, 134-140.

John MacArthur, J. D. M. P. (2014). E-Bikes in the North America : Results from an online survey.

Kajornboon, A. B. (2005). Using interviews as research instruments. E-journal for Research Teachers, 2(1), 1-9.

Konttinen, T. (2005). Cardio-Respiratory and Neuromuscular Responses to Motocross Race. Department of Biology of Physical Activity.

M. Marina1, M. R., P. Torrado1, A. Busquets3, R. Angulo-Barroso1. (2014). Force-time course parameters and force fatigue model during an intermittent fatigue protocol in motorcycle race riders. 25, 406-416. doi: 10.1111/sms. 12220

Marina, M., Torrado, P., Busquets, A., Rios, J. G., \& Angulo-Barroso, R. (2013). Comparison of an intermittent and continuous forearm muscles fatigue protocol with motorcycle riders and control group. J Electromyogr Kinesiol, 23(1), 84-93. doi: 10.1016/j.jelekin.2012.08.008

Peter, A. B., \& Julius, B. (2016). Order statistics of horse racing and the randomly broken stick: arXiv.org.

Peter, J. (2005). Racing to Relevancy. Automotive Industries, 185(1), 52-52.

Sanchez-Munoz, C., Rodriguez, M. A., Casimiro-Andujar, A. J., Ortega, F. B., Mateo-March, M., \& Zabala, M. (2011). Physical profile of elite young motorcyclists. Int J Sports Med, 32(10), 788-793. doi: 10.1055/s-0031-1279722

Sener, I. N., Lee, R. J., \& Elgart, Z. (2016). Potential Health Implications and Health Cost Reductions of Transit-Induced Physical Activity. J Transp Health, 3(2), 133-140. doi: 10.1016/j.jth.2016.02.002

Schneiders, A. G., Sullivan, S. J., Rathbone, E. J., Thayer, A. L., Wallis, L. M., \& Wilson, A. E. (2010). Visual acuity in young elite motorsport athletes: A preliminary report. Physical Therapy in Sport, 11(2), 47-49.

Zhang, Y., \& Wildemuth, B. M. (2016). Qualitative Analysis of Content. Applications of Social Research Methods to Questions in Information and Library Science, 318

Kardamanidis K, M. A., Ivers RQ, Stevenson MR, Thistlethwaite K. (2010). motorcycle rider training for the prevention of road traffic crashes. The Cochrane Library(10).

Rowden, P. J., Watson, Barry C., \& Haworth, Narelle L. (2012). Risk Taking_by Motorcyclists: Rider Training and Stages of Change.

Del Rosso, S., Abreu, L., The researcherbb, H. E., Zouhal, H., \& Boullosa, D. A. (2016). Stress markers during a rally car competition. The Journal of Strength \& Conditioning Research, 30(3), 605-614.

Kemper, H. C. G., de Vente, W., van Mechelen, W., \& Twisk, J. W. R. (2001). Adolescent motor skill and performance: Is physical activity in adolescence related to adult physical fitness? American Journal of Human Biology, 13(2), $180-189$. doi: 10.1002/1520-6300(200102/03)13:2<180::aid-ajhb1027>3.0.co;2-r

Othe researchern, N., King, H., \& Lamb, M. (2015). Literature Review of Race Driver Fatigue Measurement in Endurance Motorsport. Procedia Engineering, 112, 344-348. doi: 10.1016/j.proeng.2015.07.260

Pennington, J. A., Stumbo, P. J., Murphy, S. P., McNutt, S. W., Eldridge, A. L., McCabe-Sellers, B. J., \& Chenard, C. A. (2007). Food composition data: the foundation of dietetic practice and research. J Am Diet Assoc, 107(12), 2105-2113. doi: 10.1016/j.jada.2007.09.004

Buchheit, M., Racinais, S., Bilsborough, J. C., Bourdon, P. C., Voss, S. C., Hocking, J., . . . Coutts, A. J. (2013). Monitoring fitness, fatigue and running performance during a pre-season training camp in elite football players. J Sci Med Sport, 16(6), 550-555. doi: 10.1016/j.jsams.2012.12.003 